\title{
Neonatal Exposure to Oxidants Induces Later in Life a Metabolic Response Associated to a Phenotype of Energy Deficiency in an Animal Model of Total Parenteral Nutrition
}

\author{
NIINA KLEIBER, PHILIPPE CHESSEX, THÉRÈSE ROULEAU, ANNE-MONIQUE NUYT, MAUDE PERREAULT, \\ AND JEAN-CLAUDE LAVOIE
}

\begin{abstract}
Departments of Pediatrics [N.K., T.R., A.M.N., J.C.L.] and Nutrition [T.R., M.P. J.C.L.], CHU Sainte-Justine, University of Montréal, Montréal, Québec, Canada H3T 1C5; Division of Neonatology [P.C.], Children's and Women's Health Center of BC, University of British Columbia, Vancouver, British Columbia, Canada V6H 3P1
\end{abstract}

\begin{abstract}
Failure to protect total parenteral nutrition (TPN) from ambient light exacerbates the generation of peroxides, which affects blood glucose and plasma triacylglyceride (TG) in neonates. Based on the concept that the origin of adult diseases can be traced back to perinatal life, it was hypothesized that neonatal exposure to peroxides may affect energy availability later in life. Three-day-old guinea pigs, fitted with a jugular catheter, were fed regular chow (sham) \pm i.v. $350 \mu \mathrm{M} \mathrm{H}_{2} \mathrm{O}_{2}$ (sham $+\mathrm{H}_{2} \mathrm{O}_{2}$ ) or nourished with light-protected TPN $[\mathrm{TPN}(-) \mathrm{L}, 209 \pm 9 \mu \mathrm{M}$ peroxides] or light-exposed TPN $[\mathrm{TPN}(+) \mathrm{L}, 365 \pm 15 \mu \mathrm{M}$ peroxides]. After $4 \mathrm{~d}$, infusions were stopped and animals fed chow. Spontaneous ambulatory movements, fasting blood glucose, glucose tolerance, TG, hepatic activities of glucokinase, phosphofructokinase (key enzymes of glycolysis), and acetyl-CoA carboxylase (key enzymes of lipogenesis) were determined at $12-14 \mathrm{wk}$ and compared by ANOVA $(p<0.05)$. Relative to sham, the animals from sham $+\mathrm{H}_{2} \mathrm{O}_{2}$, TPN $(-) \mathrm{L}$ and TPN $(+) \mathrm{L}$ groups had lower plasma TG explained for $36 \%$ by low phosphofructokinase activity; they had lower glucose tolerance, lower body weight, and lower physical activity. In conclusion, neonatal exposure to oxidant molecules such as peroxides has important consequences later in life on lipid and glucose metabolism leading to a phenotype of energy deficiency. (Pediatr Res 68: 188-192, 2010)
\end{abstract}

$\mathrm{T}_{\mathrm{f}}$ he association between oxidative stress and characteristic features of the metabolic syndrome, such as diabetes, hypertension, and dyslipidemia, is well documented (1-6). Human (7) and animal studies $(8,9)$ suggest that the origin of the metabolic syndrome can be traced back to perinatal life, a time when newborn infants are at greater risk of oxidative stress caused by weak antioxidant defenses (10-12) or exposure to an oxidative environment or both (13-18). Several reports suggest that, in neonates, oxidative stress triggers the events that lead to programming of adult diseases (19-22).

Total parenteral nutrition (TPN) represents a source of oxidants in the form of peroxides that can be calibrated either by applying or not photoprotecting. The peroxides are derived from interactions between dissolved oxygen and electron donors such as lipid, amino acid, or ascorbic acid $(23,24)$. The

Received December 7, 2009; accepted May 20, 2010.

Correspondence: Jean-Claude Lavoie, Ph.D., Research Centre, CHU Sainte-Justine, 3175 Chemin de la Côte Ste-Catherine, Montréal, Quebec, Canada H3T 1C5; e-mail: jean-claude.lavoie@umontreal.ca

Supported by the Canadian Institutes of Health Research Grant MOP 77637. reaction is catalyzed by photoexcited riboflavin (24). Therefore, the main active agents participating in the generation of peroxides in TPN are ambient light $[(+) \mathrm{L}]$ and multivitamin preparations (MVP) $(23,24)$. Photoprotection $[(-) \mathrm{L}]$ of TPN reduces the levels of peroxides by close to $50 \%(23,25,26)$. Absence of photoprotection of TPN is associated in preterm newborn infants with higher urinary peroxide concentrations (16), higher blood pressure in girl babies (15), and greater blood glucose and plasma triacylglycerol concentrations (13). Hence, peroxides contaminating TPN solutions are not completely quenched by newborns infants and are thought to be an agent initiating metabolic perturbations. We questioned whether these peroxides are linked to metabolic consequences later in life.

Based on the concept that neonatal oxidative stress may interfere with metabolic programming (27), we hypothesized that neonatal exposure to peroxides such as those generated in solutions of parenteral nutrition, induces a permanent modification in lipid and glucose metabolism especially lipogenesis and/or glycolysis. Perturbations in lipid and glucose metabolism, which are fuels for energy production, could have longterm consequences on growth and physical activity, thereby affecting global development. The aim of this study was to measure in adult guinea pigs metabolic responses and spontaneous physical activity after a brief neonatal exposure to i.v. oxidant molecules limited to the first wk of life. A second objective was to assess if these modifications were related to the infusion of peroxides.

\section{MATERIALS AND METHODS}

Experimental design. The metabolic response and the levels of physical activity were compared in four groups of animals. The experiments were designed to test whether the effect of light-exposed TPN was associated to hydrogen peroxide contaminating i.v. nutritional solutions. Each one of the 3-d-old male guinea pig pups (Charles River, St-Constant, Quebec, Canada) had a catheter secured in the right jugular vein $(28-32)$ for the entire duration of the study. Animals were randomly assigned to receive one of the following regimens for $4 \mathrm{~d}$ between $\mathrm{d} 3$ and 7 of life:

Abbreviations: ACC, acetyl-CoA carboxylase-1 EC6.4.1.2; GK, glucokinase (hexokinase IV) EC2.7.1.2; PFK, phosphofructokinase-1 EC2.7.1.11.; TG, plasma triacylglycerol concentration; TPN, total parenteral nutrition; TPN(-)light, light-protected TPN; TPN(+)light, light-exposed TPN 
Sham: Animals fed exclusively by mouth (while catheter in situ) with regular chow for guinea pig (185 $\pm 25 \mathrm{kcal} / \mathrm{kg} / \mathrm{d}$; control group).

Sham $+\mathrm{H}_{2} \mathrm{O}_{2}$ : Sham animals receiving i.v. a solution containing $350 \mu \mathrm{M}$ $\mathrm{H}_{2} \mathrm{O}_{2}+0.9 \%$ (wt, vol) $\mathrm{NaCl}+1 \mathrm{U} / \mathrm{mL}$ heparin but fed by mouth regular chow ad libitum. The peroxide concentration corresponds to the level received in the $\mathrm{TPN}(+) \mathrm{L}$ group.

TPN(+)L: Animals fed exclusively with TPN (no enteral feeding) $[5.4 \mathrm{~g} / \mathrm{kg} / \mathrm{d}$ amino acids (Travasol; Baxter, Mississauga, Ontario, Canada), $3.8 \mathrm{~g} / \mathrm{kg} / \mathrm{d}$ lipids (Intralipid 20\%; Pharmacia Upjohn, Baie d'Urfé, Quebec, Canada), $8 \%$ (wt, vol) dextrose, $1 \mathrm{U} / \mathrm{mL}$ heparin, electrolytes, and 1\% MVP (Multi-12 pediatric; Sandoz, Montréal, Quebec, Canada) $=124 \pm 25$ $\mathrm{kcal} / \mathrm{kg} / \mathrm{d}]$. The i.v. solution remained without photoprotection and contained $365 \pm 15 \mu \mathrm{M}$. The level of light exposure was 75 -feet candles.

TPN(-)L: Animals fed exclusively with TPN (solution as above) protected from light $(-) \mathrm{L}$, corresponding to a peroxide concentration of $209 \pm 9 \mu \mathrm{M}$

The i.v. solutions $\left(\mathrm{H}_{2} \mathrm{O}_{2}\right.$ and TPN) were infused continuously via the jugular catheter at $220 \mathrm{~mL} / \mathrm{kg} / \mathrm{d}$ and changed daily. After $4 \mathrm{~d}$ of treatment, at $1 \mathrm{wk}$ of age, i.v. infusion was stopped, and catheters were closed by a node on its external port. Animals had free access to regular chow and water until the end of the study 13 wk later. During the first $2 \mathrm{~d}$ on regular chow (sham and TPN groups), solid food (pellet) was humidified to ensure that animals were actually feeding. Body weight was monitored each month.

During their 12th wk of age, physical activity was measured as counts of spontaneous ambulatory activity using an infrared movement detector placed in the animal cage (Digiscan DMicro Monitor; Accuscan Instruments, Inc., Columbus, $\mathrm{OH}$ ). One count corresponds to each interruption of the infrared beam by animals (Versamax Analyser; Accuscan Instruments). Counts were registered during $2 \mathrm{~h}$ (between 12 and $14 \mathrm{~h}$ ) after $1 \mathrm{~h}$ of stabilization.

At $13 \mathrm{wk}$, blood glucose was measured after $12 \mathrm{~h}$ fasting with OneTouch Ultra glucometer (Johnson \& Johnson). For the glucose tolerance test (GTT), blood glucose was determined immediately before and every $30 \mathrm{~min}$ after an i.p. injection of $2 \mathrm{~mL}$ of $50 \%$ dextrose solution $/ \mathrm{kg}$ body weight, for a total of $150 \mathrm{~min}$.

At $14 \mathrm{wk}$, after $12 \mathrm{~h}$ of fasting, blood was collected in $\mathrm{K}_{3}$ EDTA-coated tubes. After centrifugation $(3300 \times \mathrm{g}, 4 \mathrm{~min}$ at room temperature), plasma was stored at $-80^{\circ} \mathrm{C}$. The liver was removed, rinsed in $0.9 \% \mathrm{NaCl}$, rapidly minced, aliquoted, and stored at $-80^{\circ} \mathrm{C}$. Plasma triacylglyceride (TG), hepatic TG, and activities of glucokinase (GK), phosphofructokinase (PFK), and acetyl-CoA carboxylase (ACC) were determined.

Animals were housed in the animal facility with constant temperature and 12/12-h light/dark cycle. This study was approved by the Institutional Review Board for the care and handling of animals, in accordance with guidelines of the Canadian Council of Animal Care.

Analytical procedures. Peroxide concentrations in i.v. solutions were determined using ferrous oxidation-xylenol orange assay that measures a wide range of hydroperoxides (23). Triacylglycerol concentrations were determined on plasma and liver after Folch extraction using a colorimetric commercial kit (Roche Diagnostics, Laval, Quebec, Canada) (9). Hepatic ACC activity was determined as an index of the synthetic activity for lipogenesis. ACC activity was measured from 6\% PEG 8000 (Sigma Chemical-Aldrich) fraction, as previously reported $(9,33)$, and was expressed as nanomoles of malonyl-CoA produced per minute per milligram of protein (U). Hepatic GK activity $(34,35)$ was determined as the first key step enabling glucose to enter glycolysis. The GK activity was obtained by subtracting the activity measured using high glucose concentration (100 mM; total activity) from those measured with low concentration $(0.5 \mathrm{mM}$; hexokinase activity). The activity expressed as nanomoles per minute per milligram of protein (U). Hepatic PFK activity $(36,37)$ was determined as the enzyme allowing glucose-6-phosphate to be processed through glycolysis to produce ATP and pyruvate, the precursor of acetyl-CoA. PFK activity was measured on the cytosolic fraction $\left(100,000 \times \mathrm{g}\right.$ supernatant, $10 \mathrm{~min}$, and $\left.4^{\circ} \mathrm{C}\right)$ and was expressed as nanomoles per minute per milligram of protein (U).

Statistical analysis. Results were expressed as mean \pm SEM and compared by ANOVA. The null hypothesis was defined as peroxides and mode of nutrition (enteral versus parenteral) having no long-term metabolic modifications. All comparisons were orthogonal. When necessary, natural logarithm transformation was used to achieve homoscedasticity (Bartlett's $\chi^{2}$ test). The level of significance was set at $p \leq 0.05$.

\section{RESULTS}

Biochemical phenotype. Plasma TG concentrations (Fig. $1 A)$ were lower $\left(F_{1,24}=11.3\right)$ in animals that received i.v. oxidant molecules $\left[\mathrm{H}_{2} \mathrm{O}_{2}\right.$ or TPN(+)L] during their first wk of
A

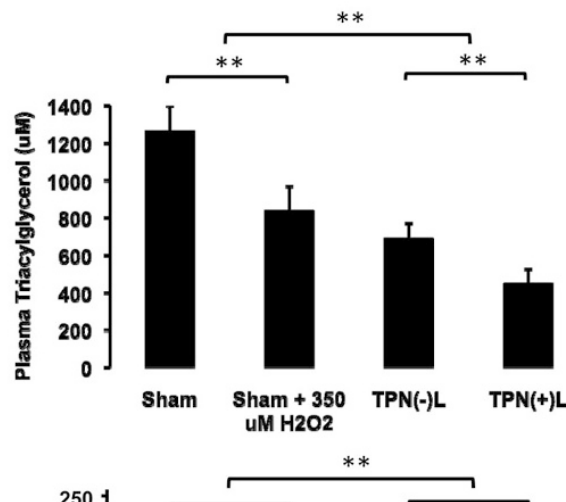

B

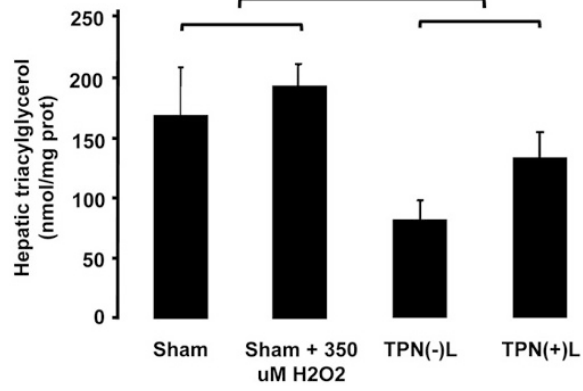

Figure 1. Concentration of triacylglycerol in plasma and liver at 14 wk of age. Sham: control animals fed with regular chow; sham $+\mathrm{H}_{2} \mathrm{O}_{2}$ : sham + infusion of $350 \mu \mathrm{M} \mathrm{H}_{2} \mathrm{O}_{2}$ between $\mathrm{d} 3$ and 7 of life; TPN(-)L: animals fed exclusively with photoprotected solution of TPN between d 3 and 7 of life; TPN $(+) \mathrm{L}$ : animals fed exclusively between d 3 and 7 of life with light-exposed TPN. Between wk 1 and 14, all animals were fed with regular guinea pig chow. Panel A, Plasma triacylglycerol concentrations were lower in groups previously exposed to $\mathrm{H}_{2} \mathrm{O}_{2}$ or TPN $(+)$ L. Panel $B$, Hepatic triacylglycerol levels were lower in groups previously exposed to TPN. (Means \pm SEM, $n=4-9$, $* * p<0.01$.)

life; plasma TG were also lower in TPN groups $\left(F_{1,24}=23.7\right)$ compared with sham groups. In liver (Fig. 1B), TG was lower $\left(F_{1,24}=9.5\right)$ only in TPN groups, in which there was no significant light effect $\left(F_{1,24}=2.5\right)$. Because the activity of ACC (Fig. 2A), a limiting enzyme in TG synthesis, was similar between groups $\left(F_{1,25}<1.1\right)$, a lower availability of substrates, such as acetyl-CoA, to sustain lipid synthesis was suspected. Because acetyl-CoA is an end product of glycolysis, the activities of two key enzymes of this pathway were investigated. Figure $2 B$ and $C$ show that neonatal exposure to i.v. oxidant molecules induced, later in life, greater GK activity $\left(F_{1,22}=11.2\right)$ and lower PFK activity $\left(F_{1,22}=14.9\right)$. There was no difference related to light exposure of TPN on both enzymes $\left(F_{1,22}<0.2\right)$, whereas the difference between TPN and $\mathrm{H}_{2} \mathrm{O}_{2}$ groups was apparent only for PFK $\left(F_{1,22}=\right.$ 9.8). Thirty-six percent of the variation in plasma TG was explained by PFK activity $(y=291 \mu \mathrm{M} / \mathrm{U} \times x-959 \mu \mathrm{M}$; $r^{2}=0.36, p<0.01$; Fig. 3), whereas the linear relation between PFK and hepatic TG was not significant $\left(r^{2}=\right.$ 0.07). Baseline blood glucose (Fig. $4 A)$ was lower $\left(F_{1,25}=\right.$ $11.5)$ in animals that received i.v. solutions containing some form of peroxides either as $350 \mu \mathrm{M} \mathrm{H}_{2} \mathrm{O}_{2}$, or as TPN(-)L that contains $\sim 200 \mu \mathrm{M}$ peroxides, or TPN $(+) \mathrm{L}$ that is contaminated with $\sim 350 \mu \mathrm{M}$ peroxides. There was no effect of light $\left(F_{1,25}=0.04\right)$ between TPN groups, which were not statistically different from the $\mathrm{H}_{2} \mathrm{O}_{2}$ group $\left(F_{1,25}=4.1\right)$. In contrast, in 30-, 60-, and 90-min postdextrose challenges (Fig. 4B), 
A

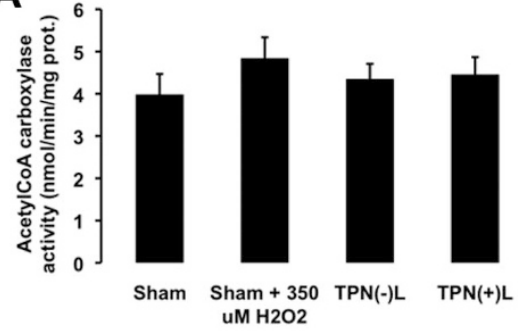

B

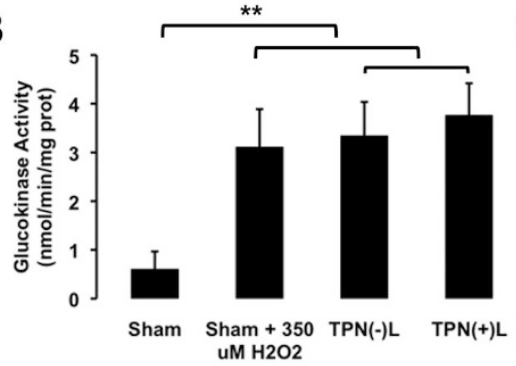

C

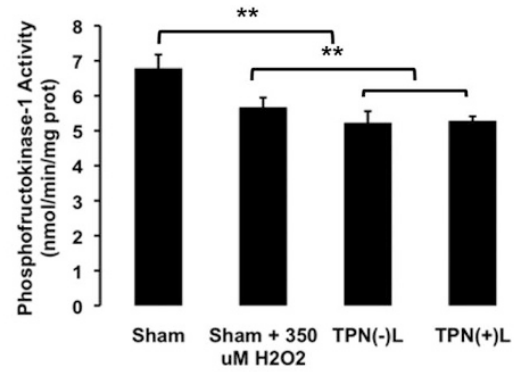

Figure 2. Hepatic activity at $14 \mathrm{wk}$ of age of key enzymes for lipogenesis and glycolysis. Sham: control animals fed with regular chow; sham $+\mathrm{H}_{2} \mathrm{O}_{2}$ : sham + infusion of $350 \mu \mathrm{M} \mathrm{H}_{2} \mathrm{O}_{2}$ between d 3 and 7 of life; TPN(-)L: animals fed exclusively with photoprotected solution of TPN between d 3 and 7 of life; TPN $(+)$ L: animals fed exclusively between d 3 and 7 of life with light-exposed TPN. Between wk 1 and 14, all animals were fed with regular chow for guinea pig. ACC activities $(A)$, a limiting step of lipogenesis, did not differ between groups. GK activities $(B)$ were higher in groups previously exposed to i.v. solutions containing peroxides. PFK activities $(C)$ were lower in groups previously exposed to i.v. solutions containing peroxides. (Means \pm SEM, $n=4-9$, $* * p<0.01$.)

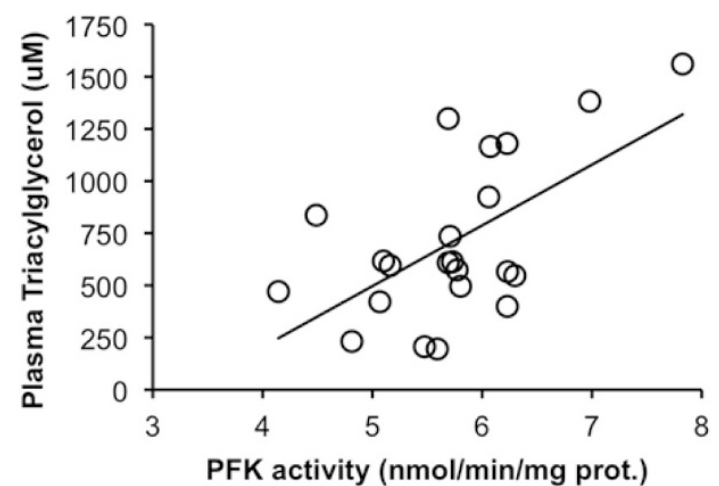

Figure 3. Linear relation between hepatic PFK activity and plasma triacylglycerol concentration at $14 \mathrm{wk}$ of age. The linear relation between PFK-1 activity and triacylglycerol concentration in plasma $(y=291 \mu \mathrm{M} / \mathrm{U} \times x$ $-959 \mu \mathrm{M} ; \mathrm{U}=\mathrm{nmol} / \mathrm{min} / \mathrm{mg}$ protein $)$ was positive $\left(r^{2}=0.36\right)$ and significant $(p<0.01)$.

blood glucose was significantly higher in the three groups of animals infused earlier with the higher concentrations of oxidant molecules (sham $+\mathrm{H}_{2} \mathrm{O}_{2}$ and $\mathrm{TPN} \pm \mathrm{L} ; F_{1,94}>4.3$ ). After $120 \mathrm{~min}$, blood glucose concentrations were highest in the $\mathrm{H}_{2} \mathrm{O}_{2}$ group $\left(F_{1,94}=3.9\right)$.

Physical phenotype. Adult body weight was affected by the neonatal i.v. feeding regimen (Fig. 5A). At the end of the infusion, by $1 \mathrm{wk}$ of age, body weights did not differ between groups $\left(F_{1,104}<0.2\right)$. As early as the first month after the neonatal i.v. feeding challenges, the body weights in the TPN groups were lower $\left(F_{1,104}=11.9\right)$ than in the sham $\pm \mathrm{H}_{2} \mathrm{O}_{2}$ groups. By 2 and 3 mo of life, all animals fed i.v. during their first wk of life with solutions containing oxidant molecules [sham $+\mathrm{H}_{2} \mathrm{O}_{2}$, TPN $(+) \mathrm{L}$, TPN $(-) \mathrm{L}$ ] had a lower body weight $\left(F_{1,104}>12.0\right)$; TPN groups remained the lightest animals $\left(F_{1,104}>7.3\right)$. There was no difference between $\mathrm{TPN}(-) \mathrm{L}$ and TPN $(+) \mathrm{L}\left(F_{1,104}<2.3\right)$.

Because perturbations in lipid and glucose metabolisms can affect energy production, spontaneous physical activity was monitored as a physiologic marker of energy expenditure (38) and, therefore, availability. Similarly to plasma TG, an additive effect of i.v. oxidant molecules and regimens $\left(F_{1,26}\right.$ $>31.2$ ) was observed on spontaneous physical activity (Fig. $5 B$ ). Animals fed i.v. with solutions containing peroxides during their first wk of life were less active later in life.
A

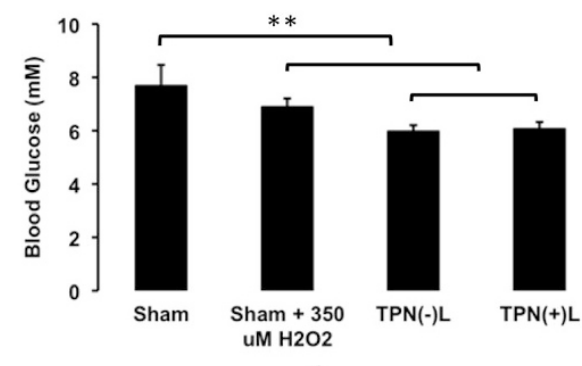

B

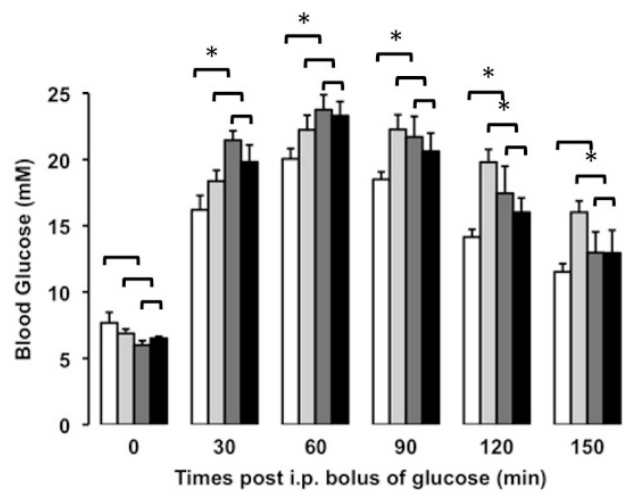

Figure 4. Blood glucose after fasting or after glucose challenge. Sham (open bar, panel B): control animals fed with regular chow; sham $+\mathrm{H}_{2} \mathrm{O}_{2}$ (lightgray bar, panel $B$ ): sham + infusion of $350 \mu \mathrm{M} \mathrm{H}_{2} \mathrm{O}_{2}$ between $\mathrm{d} 3$ and 7 of life; TPN $(-) \mathrm{L}$ (dark-gray bar, panel $B$ ): animals fed exclusively with photoprotected solution of TPN between d 3 and 7 of life; TPN(+)L (black bar, panel $B$ ): animals fed exclusively between $\mathrm{d} 3$ and 7 of life with light-exposed TPN. Between wk 1 and 14, all animals were fed with regular chow for guinea pig. Fasting blood glucose $(A)$, which corresponds to time zero of the glucose challenge, was lower in animals previously exposed to i.v. solutions containing peroxides. Between 30 and 120 min after an i.p. injection of sucrose $(B)$, blood glucose was higher in animals previously exposed to i.v. solutions containing peroxides. Differences between $\mathrm{H}_{2} \mathrm{O}_{2}$ group and TPN groups were observable at 120 and $150 \mathrm{~min}$ after glucose challenge. (Means $\pm \mathrm{SEM}, n=$ $4-9, * p<0.05 ; * * p<0.01$.)

\section{DISCUSSION}

The main finding of this study is that neonatal exposure to oxidant molecules such as TPN-generated peroxides will have important consequences, later in life, on lipid and glucose metabolism leading to a phenotype of energy deficiency. Significant developmental changes occur in the metabolic response to a neonatal oxidant challenge between the newborn period when 


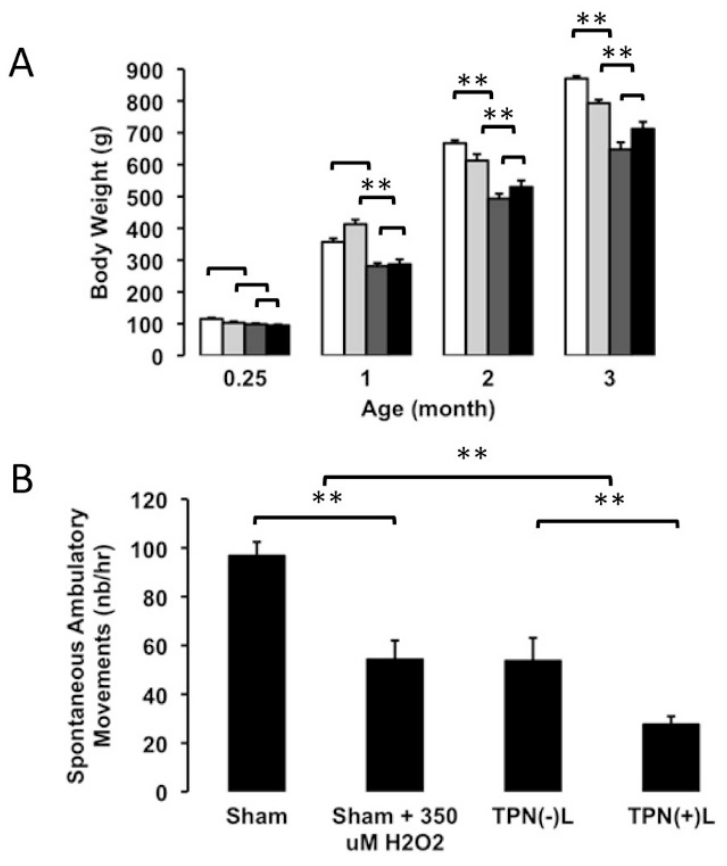

Figure 5. Body weight and spontaneous ambulatory movement at 14 wk of age. Sham (open bar, panel A): control animals fed with regular chow; sham $+\mathrm{H}_{2} \mathrm{O}_{2}$ (light-gray bar, panel $A$ ): sham + infusion of $350 \mu \mathrm{M} \mathrm{H}_{2} \mathrm{O}_{2}$ between d 3 and 7 of life; TPN(-)L (dark-gray bar, panel A): animals fed exclusively with photoprotected solution of TPN between d 3 and 7 of life; TPN (+)L (black bar, panel A): animals fed exclusively between d 3 and 7 of life with light-exposed TPN. Between wk 1 and 14, all animals were fed with regular chow for guinea pig. The early exposure to TPN induced a lighter body weight $(A)$ from the first month of age onwards, whereas the effect of neonatal exposure to $\mathrm{H}_{2} \mathrm{O}_{2}$ on body weight was observable by 2 and 3 mo of age. The spontaneous physical activity $(B)$ was decreased in animals exposed previously to peroxides. (Means \pm SEM, $n=4-9$, ** $p<0.01$.)

plasma (13) and hepatic (30) TG are increased compared with later in life, a long-time after the time-limited oxidant exposure, when the plasma and liver TG are lower than the control (Fig. 1). This suggests programming of the nutritional metabolic response after early exposure to oxidants.

The long-term effect of early neonatal i.v. exposure to peroxides was separated from the type of nutrition (oral versus parenteral; regular chow versus TPN). A significant effect induced by the type of nutrition could be explained either by a difference in the quality of nutrients or by the fact that both TPN solutions were contaminated with peroxides. This clinically tested mode of photoprotection $(13,14,15)$ reduces by half the generation of peroxides in TPN solutions $(23,25,26)$. Compared with controls, the similarity of effects on TG and blood glucose observed between the three groups suggests that even the lower amount of neonatal peroxides generated in photoprotected TPN was sufficient to induce modifications in metabolic programming later in life.

The low TG observed at 14 wk of age in animals infused earlier with solutions containing peroxides reveals an abnormal energy metabolism. The absence of modification in ACC activity oriented the investigation toward the availability of the substrate acetyl-CoA to sustain the lipid synthesis. The defect might stem from glucose uptake or the rate of glycolysis. The presence of glucose intolerance (Fig. 4B) suggests resistance to insulin, which is a powerful modulator of energy metabolism. Unfortunately, in our animal model the concentration of insulin could not be measured to test the possibility of insulin resistance, because no commercial antibody against guinea pig insulin was available. However, the low blood glucose and high GK activity observed in our animals do not support a state of insulin dysregulation. In suckling rats, a high carbohydrate diet was shown to induce, later in life, chronic hyperinsulinemia (39) and poor tolerance to oral glucose challenge $(39,40)$. A chronically high secretion of insulin could explain our observation of low blood glucose and high GK activity. Alternatively, high level of hypoxia inducible factor (HIF)-1 $\alpha$ (41) or hypomethylation of $G K$ gene promoter region $(42,43)$ are potential mechanisms accounting for high GK activity. On the other hand, high activity of GK should favor a greater availability of glucose-derived substrates for acetyl-CoA production from glycolysis. The bottleneck of glycolysis is the PFK activity, which is low in animals infused during their first wk of life with TPN or $\mathrm{H}_{2} \mathrm{O}_{2}$. The significant correlation $\left(r^{2}=0.36\right)$ between PFK activity and plasma TG supports the notion that a lower rate of glycolysis could influence plasma lipids. This lower PFK activity could be explained by a greater constitutive degradation of HIF (44) or a lower activity of AMP-activated protein kinase (45). Furthermore, increased fatty acid oxidation in the mitochondrion could generate a large quantity of citrate that would inhibit PFK activity (46). More studies are needed to shed light on these potential mechanisms.

In this study, the impact of early exposure to i.v. oxidant molecules appears to be detrimental to the physical phenotype. The lower body weight and the lower spontaneous activity observed in animals exposed to neonatal i.v. peroxides suggest that these animals produced insufficient energy to support normal growth and physical activity at the same time. In our experimental conditions, a perturbation in glucose metabolism seems to be a key event in the availability of substrates for energy production. In contrast to the initial hypothesis linking the neonatal oxidative load to the metabolic syndrome, our results shows that early exposure to oxidants induces, later in life, a lower level of blood glucose and plasma TG, which are associated to a low spontaneous physical activity when animals exhibit a normal growth rate. Further studies are needed to assess the impact of a neonatal oxidative challenge on body lipid composition in older animals whose energy consumption for growth is decreased.

Globally, the results of this study suggest that modifications in biochemical and physical phenotypes were linked to quality of nutrients early in life. Products of photooxidation would account for differences observed within the TPN groups (TG and physical activity), whereas the similarity of effects linked to TPN and the $\mathrm{H}_{2} \mathrm{O}_{2}$ load (plasma TG, GK, and PFK activities, blood glucose, body weight, physical activity) suggest that early and short exposure to peroxides has consequences into adulthood. However, the absence from the experimental design of a TPN solution without any peroxides or a sham group with an intermediate $\mathrm{H}_{2} \mathrm{O}_{2}$ concentration $(200 \mu \mathrm{M})$, which would have informed on the peroxide dose effect, represents a limitation of this study that restricts the comparison between TPN and $\mathrm{H}_{2} \mathrm{O}_{2}$ groups. The more pronounced effects of TPN (-)L on biochemical (TG and PFK) and physical phenotypes (body weight and physical activity) relative to sham $+\mathrm{H}_{2} \mathrm{O}_{2}$ suggest that compounds other than 
$\mathrm{H}_{2} \mathrm{O}_{2}$ may induce programming of lipid and glucose metabolism. Indeed, other peroxides derived from lipids (47) or ascorbic acid (48) and differences in food intake may also be important confounding variables. Beyond a lack of mechanistic explanation, the study documents an effect of neonatal exposure to $\mathrm{H}_{2} \mathrm{O}_{2}$ on metabolic programming. Are the observed effects on programming specific to peroxides or generalizable to other sources of oxidants such as oxygen? Neonatal exposure to oxidant molecules is not limited to peroxides from TPN, as many babies receive short periods of oxygen supplementation at delivery. A short period of neonatal oxygen supplementation has been shown to have serious consequences later in life $(22,49)$. Further translational studies will need to investigate the combined effect of both of these clinical relevant sources of oxidants that have been shown to induce different responses in other experimental conditions $(50,51)$.

\section{REFERENCES}

1. Kuroki T, Isshiki K, King GL 2003 Oxidative stress: the lead or supporting actor in the pathogenesis of diabetic complications. J Am Soc Nephrol 14:S216-S220

2. Yorek MA 2003 The role of oxidative stress in diabetic vascular and neural disease. Free Radic Res 37:471-480

3. Ceconi C, Boraso A, Cargnoni A, Ferrari R 2003 Oxidative stress in cardiovascular disease: myth or fact? Arch Biochem Biophys 420:217-221

4. Griendling KK, FitzGerald GA 2003 Oxidative stress and cardiovascular injury: part I: basic mechanisms and in vivo monitoring of ROS. Circulation 108:1912-1916

5. Griendling KK, FitzGerald GA 2003 Oxidative stress and cardiovascular injury: part II: animal and human studies. Circulation 108:2034-2040

6. Roberts CK, Sindhu KK 2009 Oxidative stress and metabolic syndrome. Life Sci 84:705-712

7. Barker DJ 1995 Fetal origins of coronary heart disease. BMJ 311:171-174

8. McMillen IC, Robinson JS 2005 Developmental origins of the metabolic syndrome: prediction, plasticity, and programming. Physiol Rev 85:571-633

9. Turcot V, Rouleau T, Tsopmo A, Germain N, Potvin L, Nuyt AM, Lavoie JC 2009 Long-term impact of an antioxidant-deficient neonatal diet on lipid and glucose metabolism. Free Radic Biol Med 47:275-282

10. Lavoie JC, Chessex P 1997 Gender and maturation affect glutathione status in human neonatal tissues. Free Radic Biol Med 23:648-657

11. Warner BB, Wispe JR 1992 Free radical-mediated diseases in pediatrics. Semin Perinatol 16:47-57

12. Lavoie JC, Chessex P 1998 Development of glutathione synthesis and gammaglutamyltranspeptidase activities in tissues from newborn infants. Free Radic Biol Med 24:994-1001

13. Khashu M, Harrison A, Lalari V, Lavoie JC, Chessex P 2009 Impact of shielding parenteral nutrition from light on routine monitoring of plasma glucose and triglyceride in preterm neonates. Arch Dis Child Fetal Neonatal Ed 94:F111-F115

14. Chessex P, Harrison A, Khashu M, Lavoie JC 2007 In preterm neonates, is the risk of developing bronchopulmonary dysplasia influenced by the failure to protect total parenteral nutrition from exposure to ambient light? J Pediatr 151:213-214

15. Chessex P, Khashu M, Harrison A, Hosking M, Sargent M, Lavoie JC 2010 Early life events, sex and arterial blood pressure in critically ill infants. Pediatr Crit Care Med 11:75-81

16. Laborie S, Lavoie JC, Chessex P 2000 Increased urinary peroxides in newborn infants receiving parenteral nutrition exposed to light. J Pediatr 136:628-632

17. Martin RJ, Bookatz GB, Gelfand SL, Sastre J, Arduini A, Aguar M, Escrig R, Vento M 2008 Consequences of neonatal resuscitation with supplemental oxygen. Semin Perinatol 32:355-366

18. Vento M, Sastre J, Asensi MA, Vina J 2005 Room-air resuscitation causes less damage to heart and kidney than $100 \%$ oxygen. Am J Respir Crit Care Med $172: 1393-1398$

19. Racasan S, Braam B, Koomans HA, Joles JA 2005 Programming blood pressure in adult SHR by shifting perinatal balance of NO and reactive oxygen species toward NO: the inverted Barker phenomenon. Am J Physiol Renal Physiol 288:F626-F636

20. Cambonie G, Comte B, Yzydorczyk C, Ntimbane T, Germain N, Le NL, Pladys P, Gauthier C, Lahaie I, Abran D, Lavoie JC, Nuyt AM 2007 Antenatal antioxidant prevents adult hypertension, vascular dysfunction, and microvascular rarefaction associated with in utero exposure to a low-protein diet. Am J Physiol Regul Integr Comp Physiol 292:R1236-R1245

21. Racasan S, Braam B, Van der Giezen DM, Goldschmeding R, Boer P, Koomans HA, Joles JA 2004 Perinatal L-arginine and antioxidant supplements reduce adult blood pressure in spontaneously hypertensive rats. Hypertension 44:83-88

22. Yzydorczyk C, Comte B, Cambonie G, Lavoie JC, Germain N, Shun YT, Wolff J, Deschepper C, Touyz RM, Lelievre-Pegorier M, Nuyt AM 2008 Neonatal oxygen exposure in rats leads to cardiovascular and renal alterations in adulthood. Hypertension 52:889-895

23. Lavoie JC, Belanger S, Spalinger M, Chessex P 1997 Admixture of a multivitamin preparation to parenteral nutrition: the major contributor to in vitro generation of peroxides. Pediatrics 99:E6

24. Laborie S, Lavoie JC, Chessex P 1998 Paradoxical role of ascorbic acid and riboflavin in solutions of total parenteral nutrition: Implication in photoinduced peroxide generation. Pediatr Res 43:601-606

25. Laborie S, Lavoie JC, Pineault M, Chessex P 1999 Protecting solutions of parenteral nutrition from peroxidation. JPEN J Parenter Enteral Nutr 23:104-108

26. Lavoie JC, Rouleau T, Tsopmo A, Friel J, Chessex P 2008 Influence of lung oxidant and antioxidant status on alveolarization: role of light-exposed total parenteral nutrition. Free Radic Biol Med 45:572-577

27. Luo ZC, Fraser WD, Julien P, Deal CL, Audibert F, Smith GN, Xiong X, Walker M 2006 Tracing the origins of "fetal origins" of adult diseases: programming by oxidative stress? Med Hypotheses 66:38-44

28. Lavoie JC, Rouleau T, Chessex P 2005 Effect of coadministration of parenteral multivitamins with the lipid emulsion on lung remodeling in an animal model of TPN. Pediatr Pulmonol 40:53-56

29. Lavoie JC, Rouleau T, Chessex P 2004 Interaction between ascorbate and lightexposed riboflavin induces lung remodelling. J Pharmacol Exp Ther 311:634-639

30. Chessex P, Lavoie JC, Rouleau T, Brochu P, St-Louis P, Levy E, Alvarez F 2002 Photooxidation of parenteral multivitamins induces hepatic steatosis in a neonatal guinea pig model of intravenous nutrition. Pediatr Res 52:958-963

31. Chessex P, Lavoie JC, Laborie S, Rouleau T 2001 Parenteral multivitamin supplementation induces both oxidant and antioxidant responses in the liver of newborn guinea pigs. J Pediatr Gastroenterol Nutr 32:316-321

32. Lavoie JC, Chessex P, Rouleau T, Tsopmo A, Friel J 2007 Shielding Parenteral Multivitamins from Light Increases Vitamin A and E Concentration in Lung of Newborn Guinea Pigs. Clin Nutr 26:341-347

33. Kudo N, Barr AJ, Barr RL, Desal S, Lopaschuk GD 1995 High rates of fatty acid oxidation during reperfusion of ischemic hearts are associated with a decrease in malonyl-CoA levels due to an increase in $5^{\prime}$-AMP-activated protein kinase inhibition of acetyl-CoA carboxylase. J Biol Chem 270:17513-17520

34. Xu MZ, Zhang AZ, Li XR, Xu W, Shen LW 2004 Effects of vanadate on the activities of mice glucokinase and hexokinase. J Zhejiang Univ Sci 5:1245-1248

35. Ferre T, Pujol A, Riu E, Bosch F, Valera A 1996 Correction of diabetic alterations by glucokinase. Proc Natl Acad Sci USA 93:7225-7230

36. Hamer MJ, Dickson AJ 1987 Developmental changes in hepatic fructose 2,6bisphosphate content and phosphofructokinase-1 activity in the transition of chicks from embryonic to neonatal nutritional environment. Biochem J 245:35-39

37. Karadsheh NS, Uyeda K, Oliver RM 1977 Studies on structure of human erythrocyte phosphofructokinase. J Biol Chem 252:3515-3524

38. Harris AM, McAlpine DE, Shirbhate R, Manohar CU, Levine JA 2008 Measurement of daily activity in restrictive type anorexia nervosa. Int J Eat Disord 41:280-283

39. Aalinkeel R, Srinivasan M, Song F, Patel MS 2001 Programming into adulthood of islet adaptations induced by early nutritional intervention in the rat. Am J Physiol Endocrinol Metab 281:E640-E648

40. Vadlamudi S, Hiremagalur BK, Tao L, Kalhan SC, Kalaria RN, Kaung HL, Patel MS 1993 Long-term effects on pancreatic function of feeding a HC formula to rats during the preweaning period. Am J Physiol 265:E565-E571

41. Roth U, Jungermann K, Kietzmann T 2004 Modulation of glucokinase expression by hypoxia-inducible factor 1 and upstream stimulatory factor 2 in primary rat hepatocytes. Biol Chem 385:239-247

42. Bogdarina I, Murphy HC, Burns SP, Clark AJ 2004 Investigation of the role of epigenetic modification of the rat glucokinase gene in fetal programming. Life Sci 74:1407-1415

43. Jiang MH, Fei J, Lan MS, Lu ZP, Liu M, Fan WW, Gao X, Lu DR 2008 Hypermethylation of hepatic Gck promoter in ageing rats contributes to diabetogenic potential. Diabetologia 51:1525-1533

44. Minchenko O, Opentanova I, Minchenko D, Ogura T, Esumi H 2004 Hypoxia induces transcription of 6-phosphofructo-2-kinase/fructose-2,6-biphosphatase-4 gene via hypoxia-inducible factor-1alpha activation. FEBS Lett 576:14-20

45. Marsin AS, Bertrand L, Rider MH, Deprez J, Beauloye C, Vincent MF, Van den Berghe G, Carling D, Hue L 2000 Phosphorylation and activation of heart PFK-2 by AMPK has a role in the stimulation of glycolysis during ischaemia. Curr Biol 10:1247-1255

46. Sola MM, Oliver FJ, Salto R, Gutiérrez M, Vargas A 1994 Citrate inhibition of rat-kidney cortex phosphofructokinase. Mol Cell Biochem 135:123-128

47. Silvers KM, Sluis KB, Darlow BA, McGill F, Stocker R, Winterbourn CC 2001 Limiting light-induced lipid peroxidation and vitamin loss in infant parenteral nutrition by adding multivitamin preparations to Intralipid. Acta Paediatr 90:242249

48. Lavoie JC, Chessex P, Rouleau T, Migneault D, Comte B 2004 Light-induced byproducts of vitamin C in multivitamin solutions. Clin Chem 50:135-140

49. Naumburg E, Bellocco R, Cnattingius S, Jonzon A, Ekbom A 2002 Supplementary oxygen and risk of childhood lymphatic leukaemia. Acta Paediatr 91:1328-1333

50. Chessex P, Lavoie JC, Laborie S, Vallée J 1999 Survival of guinea pig pups in hyperoxia is improved by enhanced nutritional substrate availability for glutathione production. Pediatr Res 46:305-310

51. Lavoie JC, Laborie S, Rouleau T, Spalinger M, Chessex P 2000 Peroxide-like oxidant response in lungs of newborn guinea pigs following the parenteral infusion of a multivitamin preparation. Biochem Pharmacol 60:1297-1303 